\title{
Pay Attention to the Classics and Advance with the Times--Discussion on the Integration of Classics and Fashion Elements in College Dance Teaching
}

\author{
Na Yue \\ Teachers' College of Xi'an University, 710065
}

\begin{abstract}
Keywords: Classics; Advance with the Times; College Dance Teaching; Integration of Classics and Fashion Elements
\end{abstract}

\begin{abstract}
Dance is a kind of human art which has a history of thousands of years. The graceful dance is presented by using the body language and facial expressions combined with some more distinctive movements. Dance is a very important body art, which can bring a visual feast and enjoyment. In the process of dance teaching and training, colleges and universities play a very important role. In our country's quality education system, the dance teaching in colleges and universities plays a very important role. For the reform of higher education system and the improvement of teaching level, we need to make efforts in many aspects, including the effective combination of the classic and the fashion elements, as well as combination of the traditional folkcustom and modern fashion, which will promote the dance teaching in colleges and universities well and make the art of dance full of vitality in the new historical period.
\end{abstract}

\section{Introduction}

At present, colleges and universities in our country generally offer dance courses. Whether as specialized courses or non-specialized courses, dance courses can improve students' aesthetic taste, and their physical quality and overall quality. The aesthetic level of dance is an important part of dance teaching. In the process of education promotion in our country, we are confronted with a series of important problems. Moreover, paying attention to the culture education and ignoring the quality education to a certain extent has affected the extensive development of the dance courses. At present, the education department of China requires colleges and universities to pay attention to the classics and traditional folk-custom during the dance teaching, and at the same time, the dance teaching should advance with the times and absorb some advanced fashion elements both at home and abroad.

\section{Brief Analysis of the Classical and Popular Elements of Dance Teaching}

\section{The Significance of Classical Elements in Dance Teaching}

The new curriculum reform has brought an unprecedented challenge to the traditional dance teaching. During the process of teaching dance, many colleges and universities often focus on the combination of traditional folk dance and basic stretching of body, appearance and manners, and body art, etc. The curriculum reform made the dance teaching move towards the process of international integration. During the dance teaching, it is found that all kinds of teaching modes and teaching contents embodying the spirit of the new curriculum reform can be seen in college education. The students who are not majored in dance may show weak basic skills in dance. At present, dance teaching integrates classic elements and dance elements. The teaching of basic knowledge should pay more attention to the significance of classical elements in dance teaching.

The teaching of traditional and classical dances has been somewhat limited. These visual dance performances and teaching contents actually are interlacing between dance and other disciplines. The classical dance teaching is in fact all-encompassing, including the most traditional teaching content of China. Traditional dance teaching includes the teaching of some classical chapters, classic repertoire and classical dance history. In fact, in the process of college dance teaching, classical elements and classical chapters cannot be neglected because the spread of classical dance 
skills at home and abroad is beneficial to the inheritance and development of art of dance; furthermore, the learning of some Chinese classical music and dance elements will help to develop Chinese dance art to a new height.

\section{Necessity of Applying Popular Elements in Dance Teaching}

The necessity of popular elements in dance teaching is the extended demand of current dance teaching reform, curriculum reform and innovation, and teaching idea innovation. The emphasis of dance teaching and modern dance teaching is not simply laid on imparting knowledge and skills, but also on cultivating dancers to better perceive the dance from the emotional point of view, giving the dancer the ability to create a dance. The use of popular elements in dance teaching is a brand new challenge to the traditional teaching after the new curriculum reform. This has two-sidedness. In the process of dance teaching in colleges and universities, the teachers should discard the dross and select the essential fashion factor.

It is undeniable that the combination of fashion elements and dance teaching is in fact the acceptance of a new culture. Fashionable dance and avant-garde art is the improvement of dance teaching. At present, the combination of oriental dance teaching and classical dance teaching with western modern dance teaching spreads all over the world and breaks the dogma-dominated old custom. The combined elements change the dance teaching in colleges and universities. This kind of change is a brand-new experience of using external body language for self-disclosure. It is one of the main trends in the future to give new content to dance.

\section{The Relationship between Classical Elements and Popular Elements}

The classical elements and popular elements are supplementary to each other. Traditional dancers can learn from the advanced culture and the life experience of other nations to better reflect the classical and local dance. While using fashion elements to attract the audience's attention, we can also spread the traditional culture and break the rigid standard of value between the modern world cultural patterns, so that the boundaries between the classical elements and the popular elements gradually obscure. There is a certain value scale between the traditional and the classical dance elements and the popular elements, and the value scale is in fact unified. Dance is not only a kind of emotional expression of human beings, but also a form of poetic expression and artistic explosion of human life and emotion. The combination of the classics and fashion is the inevitable demand for the integration of culture and history of human society. The interaction between people inevitably combines traditional dance and modern popular dance. The avant-garde nature and the international positioning of art not only lie in the form that the artists pursue, but also in the blending of life and emotions. What belongs to the nation also belongs to the world. Tradition and classics are the essence of dance, and the fashion is the update and innovation of dance.

\section{The Research on Application of Classical Elements in Dance Teaching in Colleges and Universities}

\section{Carrying forward the Traditional Culture and Collecting Folk Material}

The forms of folk dance in traditional culture are often long-lasting. Therefore, in the process of college dance teaching, the materials of folk dance at all times in the world can be widely collected. China is a country with cultural power which has thousands of years of artistic development history. Therefore, the localization of art is the basis of the dance teaching in colleges and universities. The dance culture of the Chinese nation goes back to ancient times, about five or six thousand years ago. As early as the Pottery Age, the dance has shown a very primitive and neat folk style. In the teaching of dance in colleges and universities, we must not ignore the traditional Chinese dance movements, dance regulations and the combination of some classical music and dance.

Since dance is the oldest forms of art of mankind, it has thousands of years of history in many ancient countries. Since the ancient times, traditional Chinese dances have experienced many stages of development and evolution, and each time the development and evolution will accumulate very essential and unique dancing art with Chinese characteristics. The dance teaching in colleges and universities of China must include these classical and long-lasting dancing art forms. This can ensure the inheritance of Chinese dancing art and can help Chinese dance step onto the world stage. 
The extensive absorption of the best traditional Chinese dance techniques, especially the most classical dance of the Han, Tang, and Song dynasties is the basis for absorbing and preserving the traditional culture of China. Therefore, dance teaching in colleges and universities should absorb the essence of these ancient dancing arts and archive them into videos for preservation and research of the traditional arts of our country.

\section{Carrying forward the National Spirit and Learning the Experience of Our Predecessors}

Chinese dance has a history of thousands of years. Many Chinese artists create wonderful dance with the music; for example, the Ba-Yu Dance and Gongme Dance of Han Dynasty, the Baizhu Dance of the Three Kingdoms, etc. In the process of the integration of dance teaching traditions and classical folk operas, we must fully carry forward the national spirit of our country. In our country, confucianism and taoism are famous. Many dance regulations follow the spiritual concepts of respecting God and elders, and harmony and beauty. At the same time, we should learn the experience of previous generations of the ancient dynasties and the essence of Chinese folk-custom and folk music. In different dynasties of China, the advocacy for dance and music differs. Different dances and music can be closely integrated with the dance teaching in colleges and universities.

\section{Research on Application of Popular Elements in College Dance Teaching}

\section{Following the Trend of the Times and Advancing with the Times}

Pop and fashionable dance is a kind of comprehensive dance that gradually evolves due to the new pursuit of dance and art after the improvement of people's living standard in the new historical period. After the prosperous period of the exchange of dance in the Tang and Qing Dynasties, China once again witnesses the climax of international dance exchange in modern times. Singing and dancing are the spiritual pursuit of people after war and poverty have been completely ended, and the result of the inevitable development of new demands. Today, China has gradually moved toward the international stage. Chinese dance has also been given new vitality in the process of dance teaching in colleges and universities. During the vigorous development of modern dance culture, the art of dance of different dynasties receives great attention. The new dance teaching also follows the trend of fashion and absorbs the fashion elements.

In China, while the art of dance has been highly developed, the confidence and magnanimity of Chinese people has also been demonstrated. Fashionable dance is often more brilliant, and also close to the taste of the younger generation. Both solo or modern dance absorb foreign fashion elements. Fashion does not mean unprofessional. The fashion may refer to making some factors of the traditional folk custom cater to modern development. The emotional pursuit and experience of dance with the creative dancing movements form an irresistible artistic power. Fashion and popular elements are closer to the common people. The popular dance elements are often dynamic. The fashion is changing with the changes of the times and merged with the traditional classics. Meanwhile, it also reflects people's daily life. The requirements for performance of the dance close to the public's emotions and daily life are not so high as those for the traditional dance, but this kind of dance is entertaining. Moreover, this kind of fashion is often positive and shows individuality.

\section{Taking the Essence of the Fashion and Discarding the Deficiencies}

Therefore, colleges and universities in the process of dance teaching must advance with the times to accept the essence of the fashionable dance and remove the deficiencies. In the process of dance teaching in colleges and universities, firstly we must cultivate the dancers' ability to perceive dance. Only by perceiving the emotions of the dance, can the dancer truly feel the dance and music; on this basis, the dance movements can be vivid with explosive power.

Therefore, in the process of dance teaching, teachers should encourage students to truly perceive all the dance energy around them, and make parts of their bodies more flexible. The music for dance should also include fashion and modern elements, and the teachers should train the students' ability to create and compose dance music. At the same time, it should be noted that in the process of teaching dance combined with popular elements, the teachers must know the different characteristics of students and conduct individualized teaching according to their aptitudes. Many university students may have to deal with various kinds of exams, they cannot be fully engaged in 
learning dance, so teachers should understand the advantages and weakness of each student in the process of dance teaching, then teach different students with different methods. In the process of teaching popular elements, the requirement for professional skills is not so high, but students are required to incorporate dance and art in an authentic manner.

\section{College Dance Teaching should Combine the Classical Elements and Popular Elements}

\section{Understanding the Basic Knowledge of Classical and Popular Dance Elements}

The national dance includes northeast yangko, the dances of the Mongol nationality, Tibetan nationality, the Dai nationality, uygur and Korean nationality. These six kinds of dance are the most common types in Chinese folk dance. Popular dance has strong self-entertainment; it is the carrier of shallow level of aesthetic awareness. Modern popular dance includes standard dance, ballroom dance, jazz, hip-hop, Latin dance, tap dance, disco, sports dance etc. Before learning to dance, we should first of all understand the essence of these types of dance.

\section{Mastering the Individual's Interest in Fashion Dances and Classical Dances}

It is undeniable that the basic skills of dance are inseparable from the classical dance. On the basis of understanding the classic movements, students can master the basic skills and distinguish the fashionable dance and classical dance, thus determine their interest and the future direction of development.

Combination of a Variety of Teaching Methods and Integration of the Classics and Fashion in Modern Teaching

Modern dance is no longer the content of debate; instead, it relies on tradition. Combining the classics and fashion to carry out art teaching in colleges and universities must use various modern teaching methods so as to enhance the students' interest in learning and lighten the teachers' teaching burden. The teachers should combine practice with video teaching to teach dance with combination of classical and popular elements.

\section{Conclusion}

In the process of college dance teaching, we must integrate the classic and popular elements, strengthen the synchronous study of the culture and knowledge, and promote the integration of classical and popular elements in dance teaching in colleges and universities. In the teaching of dance in colleges and universities, it is necessary to conduct series of reforms with integration of classical and popular elements to enhance students' learning interest and increase teaching methods. We can try to integrate folk classics and international dance, combine classics and fashion elements with dance teaching reform, so as to continuously promote the development of the dance education.

\section{References}

[1] Zhang N. Brief Analysis of Chinese Folk Dance Influenced by Modern Dance and Countermeasure [J/OL]. Art Science and Technology [2017-12-21]. http://kns.cnki.net/kcms/detail/33.1166.TN.20171130.1402.174.html.

[2] Wang L. Study on the Relationship between Chinese Dance and Traditional Culture Comments on "Dance and Traditional Culture" [J]. Journal of The Chinese Society of Education, 2017(01):118.

[3] Huang Y. Study on the Fusion of Chinese Traditional Dance and Modern Dance [D]. Southwest Jiaotong University,2015.

[4] Li M. Integration of Fashionable Dance in Aerobics Teaching Reform in Colleges and Universities [J]. Contemporary Sports Technology,2016,6(05):27-28.

[5] Zhao Y.J., Wang T. Necessity of Offering Fashionable Fitness Dance Course in Public Sports in Colleges and Universities [J]. Journal of Physical Education Institute of Shanxi Teachers University,2012,27(S2):113-115. 
[6] Zhou H.W. Research on the Current Situation and Design Promotion of Fashionable Fitness

Dance Course in Colleges and Universities in Hebei Province [D]. Hebei Normal University,2010. 